\title{
FACTOR ANALYSIS OF DIABETES MELLITUS WITH CO-EXISTING HYPERTENSION: A POPULATION-BASED STUDY FROM NORTH INDIA
}

\author{
Amit Sharma ${ }^{1}$, Ashish Baldi², and Dinesh Kumar Sharma ${ }^{3}$ \\ ${ }^{1}$ ISF College of Pharmacy \\ ${ }^{2}$ Maharaja Ranjit Singh Punjab Technical University \\ ${ }^{3}$ Roorkee College of Pharmacy
}

October 28, 2020

\begin{abstract}
Introduction: The factorial analysis of different variables like length of stay, the overall cost of the treatment, cost of medical supplies and equipment, cost of diagnostic tests, cost of the drug, lipid profile, glycaemic profile, and hypertensive profile investigations on admission is performed. Methods: In a prospective observational study, all the patients who referred to the medicine department of the three different hospitals located in Moga, City Punjab, and those who were hospitalized due to diabetes mellitus (type-I and type-II with co-existing hypertension were asked to participate in the study. Results: The patients' mean age was found to be $\mathrm{M}=$ [53.85], $\mathrm{SD}=[11.54]$ years. Out of 1914 patients, 914 were male (47.8\%), followed by female 1000 (53.65\%). The factorability of the 16 items was examined. It was observed that 14 variables are loaded onto Factor 1. It was found that 14 variables all relate to the length of stay, cost of treatment, and other lab investigations vice versa. Three variables, BPD, FBS, RBS, load onto a second factor related to each other. Discussion: This study explored the positive correlation between blood glucose profile fasting blood sugar, random blood sugar, and HbA1c, with systolic blood pressure, diastolic blood pressure. The patients' lipid profile includes cholesterol level of the patients, low-density lipoproteins, triglycerides, very-low-density lipoproteins with a length of stay, cost of drugs used, cost of the diagnostic test, and medical supplies of the patients. Conclusion: The factorial analysis revealed that length of hospital stay is positively correlated with overall all cost of the treatment, CMS: Cost of medical supplies and equipment's (INR), CT: Cost of diagnostic tests (INR), CHO, LDL, TG, VLDL creatinine level, BPS, BPD, FBS, RBS and HbA1c of the patients except CD: Cost of the drug (INR).
\end{abstract}

\section{Hosted file}

Manuscript.pdf available at https://authorea.com/users/243463/articles/489347-factoranalysis-of-diabetes-mellitus-with-co-existing-hypertension-a-population-based-studyfrom-north-india

\section{Hosted file}

Figures.pdf available at https://authorea.com/users/243463/articles/489347-factor-analysisof-diabetes-mellitus-with-co-existing-hypertension-a-population-based-study-from-northindia

\section{Hosted file}

Tables.pdf available at https://authorea.com/users/243463/articles/489347-factor-analysisof-diabetes-mellitus-with-co-existing-hypertension-a-population-based-study-from-northindia 